\title{
Dobutamine induced changes in aortic stiffness: influence of obesity in middle aged and elderly individuals with hypertension, diabetes or coronary artery disease
}

\author{
Sujethra Vasu ${ }^{1 *}$, Tim M Morgan², W Gregory Hundley ${ }^{1}$, Kimberly Lane ${ }^{1}$ \\ From 16th Annual SCMR Scientific Sessions \\ San Francisco, CA, USA. 31 January - 3 February 2013
}

\section{Background}

Previously, we have shown that increased visceral adiposity was an independent predictor of thoracic aortic wall thickness in elderly individuals at risk for future cardiovascular (CV) events. In this study, we sought to assess the influence of obesity on rest and stress induced changes in aortic stiffness in older individuals with hypertension, diabetes or coronary artery disease at risk for future CV events.

\section{Methods}

We performed dobutamine CMR on 302 consecutively referred middle aged and older individuals with hypertension, diabetes, or CAD. We assessed aortic stiffness using the ratio of pulse pressure to stroke volume index (PP/ SVI). Left ventricular stroke volume was assessed using cine MRI at rest and with peak stress. All analyses were performed by individuals blinded to the CMR imaging procedure and participant identifiers. The group was divided into tertiles based on BMI $(<27,27-32,>32)$ among 3 age groups (55-64, 65-74, 75+). The correlation between BMI expressed in tertiles and the resting PP/SVI and the changes with dobutamine was assessed using linear regression. This was tested for an interaction with age. Values are expressed as mean \pm standard error; $p$ value of $<0.05$ was considered significant.

\section{Results}

The demographics and results are shown in Figure 1. At rest there were no differences in the PP/SVI between the three BMI groups in all age groups. After dobutamine, subjects aged 55-64 in the highest BMI tertile $(>32)$ had an increase in the PP/SVI by $0.115 \pm 0.105$ similar to that of subjects aged $75+$ in the highest BMI tertile, $0.205 \pm 0.168$ (Figure 2). In contrast, both both subjects aged 55-64 and $75+$ in the low and medium BMI tertiles experienced a decrease in the PP/SVI with dobutamine, $-0.122 \pm 0.133$ and $-0.150 \pm 0.086$ for the $55-64$ age group and -0.290 \pm 0.115 and $-0.044 \pm 0.089$ in the $75+$ age group. After adjusting for age and gender, stress PP/SVI and the change in PP/SVI had a significant association with BMI ( $\mathrm{p}=0.005$ and $\mathrm{p}<0.0001$ ) respectively. Age had a significant interaction in this relationship $(\mathrm{p}=0.02)$, whereas fasting glucose did not have a significant interaction.

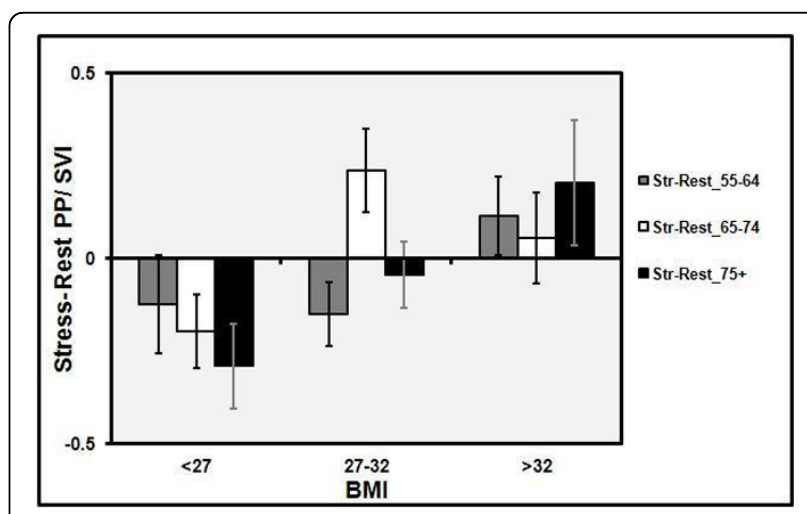

Figure 1 Change in PP/SVI: Stress- Rest 
Table 1 Demographics and results

\begin{tabular}{|c|c|c|c|c|}
\hline Measure & $\mathrm{BMl}<27.45(\mathrm{~N}=98)$ & BMI 27.45-32 ( $\mathrm{N}=101)$ & $\mathrm{BMI}>32(\mathrm{~N}=103)$ & $\mathrm{p}$-value with $\mathrm{BM}$ \\
\hline Age & $70.3(8.0)$ & $68.9(7.8)$ & $66.6(8.0)$ & 0.0003 \\
\hline $55-64$ & $24(24.5 \%)$ & $35(34.6 \%)$ & $48(46.6 \%)$ & \\
\hline $65-74$ & $40(40.8 \%)$ & $38(37.6 \%)$ & $34(33.0 \%)$ & \\
\hline $75+$ & $34(34.7 \%)$ & $28(27.7 \%)$ & $21(20.9 \%)$ & \\
\hline Female & $50(51.0 \%)$ & $47(46.5 \%)$ & $71(68.9 \%)$ & 0.018 \\
\hline Race & & & & 0.0017 \\
\hline Caucasian & 88 (89.8\%) & $80(79.2 \%)$ & 71 (68.9\%) & \\
\hline African Am. & $6(11.1 \%)$ & $17(31.5 \%)$ & $31(30.1 \%)$ & \\
\hline Prior HTN & $88(89.8 \%)$ & $92(91.0 \%)$ & $98(95.2 \%)$ & 0.23 \\
\hline Prior DM & & & & 0.018 \\
\hline None & $64(65.3 \%)$ & $60(59.4 \%)$ & $55(53.4 \%)$ & \\
\hline$<5$ years & $34(34.7 \%)$ & $33(32.7 \%)$ & $40(38.8 \%)$ & \\
\hline$=5$ years & 0 & $8(7.9 \%)$ & $8(7.8 \%)$ & \\
\hline Prior CAD & $27(27.6 \%)$ & $22(21.8 \%)$ & $16(15.5 \%)$ & 0.34 \\
\hline SQ fat & $143.1(56.7)$ & $202.9(73.7)$ & $325.5(132.4)$ & $<0.0001$ \\
\hline Visceral fat & $142.6(72.6)$ & $197.3(94.7)$ & $238.4(97.8)$ & $<0.0001$ \\
\hline \multicolumn{5}{|l|}{ Taking drugs } \\
\hline ACE & $48(49.0 \%)$ & $50(49.5 \%)$ & $39(37.9 \%)$ & 0.27 \\
\hline ARB & $4(4.2 \%)$ & $4(4.2 \%)$ & $3(2.9 \%)$ & 0.73 \\
\hline Statin & $64(65.4 \%)$ & $64(65.4 \%)$ & $69(67.0 \%)$ & 0.82 \\
\hline Beta blocker & 45 (45.9\%) & $45(45.9 \%)$ & $41(39.8 \%)$ & 0.43 \\
\hline Ca Ch. BL. & $23(23.5 \%)$ & $23(23.5 \%)$ & $25(24.5 \%)$ & 0.67 \\
\hline Rest_55-64 & $1.618 \pm 0.119$ & $1.528 \pm 0.096$ & $1.45 \pm 0.069$ & \\
\hline Stress_55-64 & $1.528 \pm 0.107$ & $1.371 \pm 0.103$ & $1.513 \pm 0.092$ & \\
\hline Rest_65-74 & $1.719 \pm 0.074$ & $1.63 \pm 0.075$ & $1.739 \pm 0.089$ & \\
\hline Stress_65-74 & $1.537 \pm 0.07$ & $1.842 \pm 0.102$ & $1.701 \pm 0.084$ & \\
\hline Rest_75+ & $1.898 \pm 0.08$ & $1.848 \pm 0.103$ & $1.79 \pm 0.088$ & \\
\hline Stress_75+ & $1.694 \pm 0.11$ & $1.784 \pm 0.123$ & $1.962 \pm 0.152$ & \\
\hline
\end{tabular}

\section{Conclusions}

Middle aged and elderly subjects with BMI $>32$ have increased aortic stiffness after dobutamine stress in contrast to those with $\mathrm{BMI}<32$. The prognostic significance of the increased aortic stiffness with stress in obese individuals and its relationship to ventricular remodeling deserve further study.

\section{Funding}

NIH R01 HL076438 Dr. W Gregory Hundley.

\section{Author details}

${ }^{1}$ Cardiology, Wake Forest University School of Medicine, Winston-Salem, NC, USA. ${ }^{2}$ Public Health, Wake Forest Unviersity School of Medicine, WinstonSalem, NC, USA.

Published: 30 January 2013
doi:10.1186/1532-429X-15-S1-045

Cite this article as: Vasu et al:: Dobutamine induced changes in aortic stiffness: influence of obesity in middle aged and elderly individuals with hypertension, diabetes or coronary artery disease. Journal of Cardiovascular Magnetic Resonance 2013 15(Suppl 1):O45.
Submit your next manuscript to BioMed Central and take full advantage of:

- Convenient online submission

- Thorough peer review

- No space constraints or color figure charges

- Immediate publication on acceptance

- Inclusion in PubMed, CAS, Scopus and Google Scholar

- Research which is freely available for redistribution

Submit your manuscript at www.biomedcentral.com/submit 